\title{
Nursing student community engagement barriers, facilitators and satisfaction: Perceptions of Community Champions
}

\author{
Evangeline Chen, Naun Kim, Emily Webster, Claire Bocage, Terri H. Lipman* \\ University of Pennsylvania School of Nursing, Philadelphia, PA, USA
}

Received: June 14, 2021

Accepted: July 7, 2021

Online Published: July 30, 2021

DOI: $10.5430 /$ jnep.v11n $11 \mathrm{p} 81$

URL: https://doi.org/10.5430/jnep.v11n11p81

\begin{abstract}
Nursing students could benefit professionally by participating in community engagement, but barriers to student involvement in community engagement exist. Community Champions, a nursing student-led, faculty-mentored service-learning group, promotes local outreach and engagement with a variety of community initiatives for nursing students. The purpose of this study was to examine former and current Community Champions' perceptions of the barriers and facilitators to participating in community engagement initiatives, as well as their satisfaction with the community engagement initiatives. The study used a 14-item survey, consisting of both Likert-scale items and open-ended questions. Of the 130 Community Champions invited to complete the survey, 40 Community Champions responded (30.8\% response rate). Quantitative responses were analyzed using descriptive statistics, and qualitative responses were reviewed for themes to generate future recommendations for program improvement. Respondents rated Community Champions highly and reported personal and professional benefits to community engagement. Reasons for program satisfaction were synthesized into "opportunities for interactions with diverse community members", "stress relief", and "professional development"; reasons for program dissatisfaction were summarized as "disorganization of community sites", "competing academic priorities", and "lack of information". Academic student programs that engage the community can positively impact both the community partners and university students.
\end{abstract}

Key Words: Program evaluation, Community engagement, Volunteer, Professional development

\section{INTRODUCTION}

\subsection{Introduce the problem}

During the formative years of nursing education, community engagement, defined as "the process of working collaboratively with and through groups of people affiliated by geographic proximity, special interest, or similar situations to address issues affecting the well-being of those people", ${ }^{[1]}$ allows nursing students to improve the vital skill of health education and promotion, such as a sense of self-efficacy to examine the various factors that influence health. ${ }^{[2]}$ Additionally, community engagement can help cultivate leadership, critical thinking, professional decision making, and social awareness in nursing students. ${ }^{[3]}$ Using these skills, nurses may be further motivated to participate in meaningful research and advocate for health care policies that will affect their communities. ${ }^{[4]}$

However, there can be many barriers to participating in meaningful community engagement activities for students enrolled USA.

*Correspondence: Terri H. Lipman; Email: lipman@ nursing.upenn.edu; Address: University of Pennsylvania School of Nursing, Philadelphia, PA, 
in a nursing program. Nursing students have demanding course loads, long clinical hours, and changing schedules. Furthermore, community engagement requires a planned approach and clear guidelines describing roles and responsibilities for students. ${ }^{[4]}$ Previous studies have demonstrated a need for practical guidelines for communication between students, faculty, and community partners. ${ }^{[3]}$ Cited barriers to community engagement include lack of dedicated staff and resources, low awareness of engagement opportunities, and lack of organizational commitment. ${ }^{[5]}$ Exploring these barriers can help develop a more comprehensive approach to engaging and supporting nursing students involved in community health initiatives.

Community Champions is a nursing student-led, facultymentored service-learning organization at the University of Pennsylvania School of Nursing. ${ }^{[6-8]}$ Founded in 2014, the program aims to deepen undergraduate and accelerated nursing students' understanding of specific health needs of the greater Philadelphia community and promote population health in a variety of different settings. Community Champions are committed to community engagement beyond the community health coursework requirement in the senior year of the baccalaureate nursing program. Students are also provided with faculty mentorship and guidance. The Community Champions program is rooted in mutually beneficial partnerships with several community organizations. Nursing students directly engage with community members as health educators, mentors, and healthcare providers. Opportunities include providing hypertension education and screenings at local barber shops, teaching health education classes at elementary schools, and working with an interdisciplinary team to provide care at a free clinic. Currently, 60 undergraduate nursing students are involved in the program.

The purpose of this study was to assess Community Champions' perceptions of the barriers and facilitators to participating in community engagement initiatives, as well as the satisfaction of current and past members of Community Champions with the community engagement initiatives. The study also explored potential recommendations for program improvement.

\section{METHOD}

This cross-sectional survey was conducted using the online survey software Qualtrics (Qualtrics, Provo, Utah).

\subsection{Participants}

Participants included University of Pennsylvania traditional 4-year baccalaureate nursing students and undergraduate nursing students who had a previous undergraduate degree who had graduation years ranging from December 2019 to
May 2023 (expected graduation date).

\subsection{Data collection}

The surveys were distributed via email to past and present Community Champions members on a Community Champions email list-serve between 2019-2020. Participants were asked to complete a 14-question survey that included questions using a Likert scale and open-ended questions describing their satisfaction with the program, as well as any barriers to participating in community engagement initiatives. Survey questions included year in the nursing program, community engagement initiative, number of semesters involved with Community Champions, and average number of hours devoted to their initiative each week. Participants were also asked to rate their satisfaction with the overall program, their community engagement initiative, and the contribution of the Community Champion experience to their professional development with a 5-point Likert scale (1 - Dissatisfied, 2 Somewhat dissatisfied, 3 - Neither, 4 - Somewhat satisfied, 5 - Satisfied).

\subsection{Data analysis}

Survey responses were anonymous, and each participant was given a unique identifier. Only respondents that served at least one semester at a community engagement initiative, completed all demographic questions, and completed all Likert questions were included in the analysis. Frequencies were used to analyze quantitative survey data. Open-ended survey responses to satisfaction ratings, as well as participants' primary reasons for joining Community Champions, feedback they would give to their site, and barriers to participating were analyzed using content analysis. The qualitative survey data were independently analyzed by two authors (E.C., N.K.).

\subsection{Ethical considerations}

This project was determined to be a program evaluation and did not seek Institutional Review Board review.

\section{RESUlts}

Quantitative and qualitative results are described below.

\subsection{Participants}

Data collection occurred from February 2020-April 2020. Of the 130 current and past Community Champions contacted, $40(30.8 \%)$ responded to our survey. Graduation year of participants ranged from 2019 to $2023 ; 28$ (75\%) were in the traditional baccalaureate program and $12(25 \%)$ were in the second degree accelerated nursing program (see Table 1). 
Table 1. Respondents by current academic standing

\begin{tabular}{ll}
\hline Year & Total Number \\
\hline Traditional Freshman & $4(10 \%)$ \\
Traditional Sophomore & $3(7.5 \%)$ \\
Traditional Junior & $7(17.5 \%)$ \\
Traditional Senior & $12(28.3 \%)$ \\
Accelerated Student & $12(28.3 \%)$ \\
Graduate/Alumni & $2(5 \%)$ \\
\hline
\end{tabular}

The participants were engaged in a wide variety of community engagement initiatives in the West Philadelphia area. Several nursing students participated in multiple initiatives during their membership in Community Champions. Number of semesters involved in Community Champions ranged from 1 to 8 semesters and members reported engaging at a site for 1 to 3 hours a week.

\subsection{Statistics and Data Analysis}

Participants rated the Community Champions program highly, with an average rating of 4.67. Notably, all satisfaction scores were a rated 3 or higher, indicating that no participant was somewhat dissatisfied or dissatisfied with their experience in Community Champions. Participants engaged with the Community Champions program for less time (1-2 semesters), were more likely to report lower satisfaction scores (i.e., of the 11 participants' satisfaction scores of neutral or somewhat satisfied, $90.1 \%$ were involved with the program for 1-2 semesters (see Table 2).

Table 2. Satisfaction scores by number of semesters engaged

\begin{tabular}{llll}
\hline $\begin{array}{l}\text { Number of semesters } \\
\text { involved }\end{array}$ & Total Number of Participants & $\begin{array}{l}\text { Average Satisfaction } \\
\text { Score }\end{array}$ & $\begin{array}{l}\text { Average Agreement with Professional } \\
\text { Development Score }\end{array}$ \\
\hline $1-2$ & $28(70 \%)$ & 4.57 & 4.54 \\
$3-4$ & $5(12.5 \%)$ & 5 & 4.6 \\
$5-6$ & $5(12.5 \%)$ & 4.8 & 4.8 \\
$>6$ & $2(5 \%)$ & 5 & 4.5 \\
All & 40 & 4.67 & 4.58 \\
\hline
\end{tabular}

\subsubsection{Professional Development and Analysis}

Participants were asked if Community Champions was beneficial for professional or nursing development. The average score for the benefit of Community Champions for professional or nursing development was 4.58. Of a total of 40 participants, 27 (67.5\%) participants answered "agree," 9 $(22.5 \%)$ participants answered, "somewhat agree," and four (10\%) participants answered, "neither agree nor disagree." Those that were engaged at sites for 5-6 semesters reported the highest agreement that Community Champions was beneficial for their nursing professional development; those engaged at sites for 1-2 semesters or more than six semesters reported the lowest agreement scores (see Table 2).

\subsubsection{Motivations for Joining and Retention in the Com- munity}

Most participants responded that they joined to be involved in the greater West Philadelphia community (55\%), followed by elective course requirements $(27.5 \%)$, and desire to further their personal or professional development $(17.5 \%)$. When asked how likely participants would be to recommend Community Champions to other nursing student peers, 35 (87.5\%) participants responded "likely," four (10\%) participants responded, "somewhat likely," and one $(2.5 \%)$ participant responded, "neither unlikely or likely." We also asked if partic- ipants would continue to be involved in a community organization, 29 (72.5\%) participants responded “yes," 11 (27.5\%) participants responded "maybe," and zero $(0 \%)$ participants responded "no."

\subsubsection{Barriers to Involvement and Manageability}

Twenty-four $(60 \%)$ participants did not experience barriers and participated in every semester since joining Community Champions. Thirteen (32.5\%) students responded having conflicting responsibilities, such as classes, work, or clinical responsibilities, and three $(7.5 \%)$ responded "Community Champions site was not beneficial to my personal and/or professional development". There were no participants who selected "miscommunication about what was expected at the site" or "the site I was originally involved in discontinued." Two (5\%) participants chose "other".

When asked about the manageability of being involved with Community Champions with participants' course work, 27 (67.5\%) participants responded "manageable," 10 (25\%) participants responded, "somewhat manageable," two (5\%) participants responded, "somewhat unmanageable," and one (2.5\%) participant responded, "neither unmanageable nor manageable". 


\subsection{Qualitative results}

Thematic results from the open-ended survey responses are described below, describing what respondents self-reported as reasons for satisfaction or dissatisfaction with Community Champions. All supporting quotes for each theme can be found in the Appendix.

\subsubsection{Reasons for satisfaction - Opportunities for interac- tions with diverse community members}

Many participants commented about their involvement in the Philadelphia community as the most beneficial aspect to participating in Community Champions. These participants highlighted the value of going to various parts of Philadelphia and being able to learn, firsthand, the lived experience of those in the community. Community Champions is structured to foster mutually beneficial partnerships with community organizations and Community Champions reported that their work meaningfully contributed to the community they served. Through service, the Community Champions organization allowed students to engage with parts of the city to which they are not usually engaged and develop relationships with those outside of the University.

\subsubsection{Reasons for satisfaction - Professional Development}

Respondents also appreciated the opportunities to develop their nursing skills for future practice since working in the community provided additional environments to exercise hard and soft skills learned in the nursing program. Engaging in these settings also enhanced one student's knowledge and perceived importance of health education. Participants reported that the communication and interpersonal skills gained through their Community Champions experience were invaluable for their future nursing careers. The sites that facilitated nursing engagement and a sense of professional accomplishment were sites with particular focus on health education and for some, direct one-on-one teaching. Being able to educate community members on important health topics may have contributed to the overall perceived professional development.

\subsubsection{Reasons for satisfaction - Stress relief}

Several participants stated that even after a busy week they still wanted to attend their community initiative. Community Champions allowed students to break up their routine of schoolwork and go outside of the school campus. Respondents suggested that the community engagement allowed them to separate themselves from their schoolwork and relieve stress.

\subsubsection{Reasons for dissatisfaction - Disorganization of community sites}

Several participants cited community site disorganization and miscommunication as a source of student dissatisfaction.
These included sites that were unprepared to take students, unable to effectively articulate program requirements, or unable to maintain a consistent schedule for students. Respondents cited these factors as barriers to satisfaction and potential contributors to a negative experience with Community Champions as a whole.

\subsubsection{Reasons for dissatisfaction - Competing academic priorites}

Participants reported that extensive coursework alongside other extracurricular activities can make participation in community sites difficult. These competing academic priorities were reported as barriers to engaging in Community Champions earlier on in their undergraduate career. Additionally, some participants identified that community sites required too much of their time which was a barrier to student engagement. Respondents expressed a need to prioritize coursework and some flexibility when engaging at a site. Articulating site expectations may need to be explained in further depth to clarify what expectations Community Champions require of students before they choose to join. Students may also need to have a better understanding of what their academic course load entails prior to joining Community Champions.

\subsubsection{Reasons for dissatisfaction - Lack of information}

Lastly, another barrier shared by a Community Champion was lack of knowledge about the program and how the initiatives operated. This could indicate that there was not enough information presented to prospective students or miscommunication about the program.

\section{DisCUSSION}

A variety of factors contributed to student satisfaction with Community Champions. We examined the length of involvement and type of community initiative for each student to explain the degree of satisfaction. Of those who responded to the survey, $72.5 \%$ were satisfied with their experience and no current or past member of Community Champions was dissatisfied with their experience. Satisfaction could also be explained by specific experiences within the community, such as meaningful interaction with diverse community members, perceived professional development, or stress relief. Qualitative data from a similar study demonstrated that service learning facilitated increased social confidence, increased leadership ability, increased interpersonal skills, and increased understanding of problems facing the community and the nation. ${ }^{[2,9]}$ Students may be motivated to continue with community engagement because of the perceived personal and professional development gained.

Participants who commented about their experience agreed that one of the most beneficial parts of Community Cham- 
pions was the opportunity to leave the school campus and go into the Philadelphia community. A previous study stated that community experiences enhanced their appreciation of people from diverse backgrounds and increase their sense of global awareness. ${ }^{[2]}$ Developing meaningful relationships in the community allowed for students to become more invested in those communities in the future. One study found that continuity in the community promoted trust, which fostered the sense of investment that contributed to effective partnerships ${ }^{[10]}$ Moreover, community engagement has been shown to allow nursing students to become more culturally competent and facilitate personal and professional development. ${ }^{[11]}$ A previous study demonstrated that students engaged in the service learning were inspired to teach and sponsor community health promotions in their future clinical practice. ${ }^{[12]}$ This was congruent with our data that showed that $72.5 \%$ of participants said they would continue to be involved in community engagement in future or after graduating. Many positive experiences respondents shared demonstrated a sense of fulfillment related to their community work and a desire to return in the future.

Respondents discussed barriers to community engagement due to site disorganization, miscommunication, or competing academic priorities. Previous studies have also shown that lack of clarity and confused expectations around community engagement goals and processes, and administrative delays for community volunteers or leaders were barriers to effective community engagement. ${ }^{[5]}$ Additionally, students chose not to participate due to competing academic priorities, such as the priority of adjusting to college or other heavy academic coursework. However, the positive effects of volunteering on academic development, can counteract the time and energy that the student might otherwise devote to academic pursuits. ${ }^{[2,9]}$ These areas would be particularly beneficial for Community Champions to explore and address specifically for future student involvement.

Respondents citing stress relief as a program benefit adds to a growing body of work examining the relationship between civic engagement and health outcomes ${ }^{[13]}$ which the Community Champions program or other researchers can explore further. Stress from both academic and clinical demands is frequently cited to be elevated for nursing students compared to other baccalaureate students: ${ }^{[14]}$ this stress can lead to negative educational outcomes, such as dropping out of a nursing program. ${ }^{[15,16]}$ Community engagement could be a potential intervention to reduce nursing student stress, since respondents cited professional development, and the space to practice skills, as a program benefit; this aligns with prior research which suggested that problem-solving and information-seeking to enhance clinical competency are fre-

Published by Sciedu Press quently cited among nursing students as strategies to reduce stress. ${ }^{[14,17]}$ However, more robust research to evaluate how community engagement impacts stress in nursing students is needed.

There were several limitations to this study. Most of participants of the study were only involved in Community Champions for one or two semesters, so the data are skewed towards those with less experience. Since we recruited participants from the Community Champion's list-serve, the opinions of former Community Champions that have chosen to opt-out or remove themselves from the list-serve are not captured. This could result in self-response bias as those who were more satisfied with Community Champions were more likely to want to remain engaged with Community Champion communications; alternatively, those that were more dissatisfied with the program might have been more inclined to give program feedback. However, our sample size $(n=40)$ is generally considered large enough for analytical statistics and the purpose of this study was to describe program satisfaction, not generate statistical associations between variables. Lastly, open ended responses were not required in the survey response from each participant. Elaboration was voluntary, so the amount of qualitative data we were able to collect from all 40 respondents was limited.

Moving forward, we would suggest another survey with a larger sample size and a more diverse sample group that includes an evenly distributed number of students who have been involved for more than two semesters and in a wide variety of community initiatives. This would hopefully capture a greater impact of length of involvement and type of initiative on satisfaction with community engagement and Community Champions as a community engagement organization. We would also recommend a more extensive survey that studies whether the number semesters involved, or type of community initiative impacted other factors that we did not analyze specifically for this survey, such as barriers to involvement, future career goals, and recommending Community Champions to other students.

\section{Conclusion}

The importance of community health nursing in advancing health equity was highlighted in the Future of Nursing 20202030 report. ${ }^{[18]}$ Nursing schools often seek strategies for meaningful student engagement with communities. Community Champions, a service-learning organization, received high satisfaction scores by former students due to meaningful interaction with diverse community members and the impact on professional development. The constraints of academic course load that limited available time for community engagement, as well as unclear communication or expectations 
from community sites were cited as barriers. Curricula that provide credit bearing experiences for community service learning can serve to enhance course work and ameliorate the scheduling challegses of community engagement. Future research could examine how student community engagement impacts nursing practice after graduation.

\section{ACKNOWLEDGeMENTS}

We would like to thank the respondents for their time, as well as Kierstin Knellinger and Theresa McShea for providing manuscript support.

\section{CONFlicts OF InTEREST Disclosure}

The authors declare that there is no conflict of interest.

\section{REFERENCES}

[1] Clinical and Translational Science Awards (CSTA) Consortium Community Engagement Key Function Committee Task Force on Principles of Community Engagement. Principles of community engagement. 2nd ed. [Internet]. 2011; NIH Publication No. 11-7782. Available from: http://www.atsdr.cdc.gov/communityengag ement/pdf/PCE_Report_508_FINAL.pdf

[2] Montgomery M, Johnson P. Increasing nursing students' knowledge of health promotion through community engagement. Pedagogy in Health Promotion. [Internet]. 2015; 1(3): 153-57. Available from: https://journals-sagepub-com.proxy.library.upe nn.edu/doi/full/10.1177/2373379915577964 https://do i.org/10.1177/2373379915577964

[3] Schaffer MA, Hargate C. Moving toward reconciliation: Community engagement in nursing education. Journal of Community Engagement and Scholarship. 2015; 8(1). Available from: https: //digitalcommons.northgeorgia.edu/jces/vol8/iss1/7/

[4] Clearly M, Hunt GE. Building community engagement in nursing. The Journal of Continuing Education in Nursing. 2010; 41(8): 344-5. PMid:20666354 https://doi .org/10.3928/00220124-20100 726-04

[5] Harden A, Sheridan K, McKeown A, et al. Review 5: Evidence review of barriers to, and facilitators of, community engagement approaches and practices in the UK. London: Institute for Health and Human Development, University of East London (UK); [Internet] 2015 Oct. Available from: https://repository.uel.ac.uk/i tem/85208

[6] Hausman-Cohen S, Asamoah N, Yee C, et al. Community organizations' perspectives on the impact of a nursing student-led academiccommunity partnership program. Journal of Nursing Education and Practice. 2020; 10(8): 9-15. https://doi.org/10.5430/jnep.v 10n8p9

[7] Benson CE, Feinberg J, Abdallah A, et al. Community champions: A mixed methods study on volunteer recruitment and retention in community engagement. Journal of Nursing Education and Practice. 2020; 10(6): 19-25. https://doi.org/10.5430/jnep.v10n6p19

[8] Mintz SR, Low CA, McCurry IJ, et al. The Community Champions program at the University of Pennsylvania School of Nursing. Journal of Nursing Education and Practice. 2017; 7(8): 46-50. https://doi.org/10.5430/jnep.v7n8p46

[9] Astin AW, Sax LJ. How undergraduates are affected by service participation. Service Participation. 1998; 39(3): 251.
[10] Wattman JE, Schaffer MA, Juarez MJ, et al. Community partner perceptions about community engagement experiences for nursing students. Journal of Community Engagement and Higher Education. 2009; 1(1). Available from: https://discovery. indstate.edu /jcehe/index.php/joce/article/view/8

[11] Hunt RJ, Swiggum P. Being in another world: Transcultural student experiences using service learning with families who are homeless. Journal of Transcultural Nursing. 2007; 18(2): 167-174. PMid:17416719 https://doi.org/10.1177/10436596062986 14

[12] Bassi S. Undergraduate nursing students' perceptions of service learning through a school-based community project. Nursing Education Perspectives. 2011; 32(3): 162-167. PMid:21834377 https : //doi.org/10.5480/1536-5026-32.3.162

[13] Nelson C, Sloan J, Chandra A. Examining civic engagement links to health: Findings from the literature and implications for a culture of health. RAND Corporation. 2019. Available from: https: //www.rand.org/pubs/research_reports/RR3163.html

[14] Labrague LJ, McEnroe-Petitte DM, Gloe D, et al. A literature review on stress and coping strategies in nursing students. Journal of Mental Health. 2017; 26(5): 471-80. PMid:27960598 https : //doi.org/10.1080/09638237.2016.1244721

[15] Sheu S, Lin HS, Hwang SL. Perceived stress and physio-psychosocial status of nursing students during their initial period of clinical practice: The effect of coping behaviors. International Journal of Nursing Studies. 2002; 39(2): 165-75. https://doi.org/10.101 6/S0020-7489(01) 00016-5

[16] Watson R, Deary I, Thompson D, et al. A study of stress and burnout in nursing students in Hong Kong: A questionnaire survey. International Journal of Nursing Studies. 2008; 45: 1534-42. PMid:18241870 https://doi.org/10.1016/j.ijnurstu. 200 7.11 .003

[17] Rafati F, Nouhi E, Sabzevari S, et al. Coping strategies of nursing students for dealing with stress in a clinical setting: A qualitative study. Electronic physician. [Internet]. 2017; 9(12): 6120-6128. PMid:29560168 https://doi .org/10.19082/6120

[18] National Academies of Sciences, Engineering, and Medicine, Committee on the Future of Nursing 2020-2030. Future of Nursing 2020-2030: A consensus study from the National Academy of Medicine. Washington (DC): National Academies Press; 2021. Available from: https://nam.edu/publications/the-future-o f-nursing-2020-2030/ 